Eixo Temático: Desenvolvimento de Estratégias Didáticas

\title{
ET-07-011 \\ “TWISTER ESTELAR": UM JOGO INTERATIVO PARA APRENDENTES DO SEXTO ANO DO ENSINO FUNDAMENTAL
}

\author{
Leiliane Silva dos Santos ${ }^{1,3}$, Lys Ayanne Dias Santos ${ }^{13}$, Eltamara Conceição ${ }^{2,3}$ \\ ${ }^{1}$ Bolsista do Programa Institucional de Bolsas de Iniciação a Docência. \\ ${ }^{2}$ Coordenadora de Área do PIBID. Universidade do Estado da Bahia. \\ ${ }^{3}$ Departamento de Ciências Exatas e da Terra II - Campus II, UNEB, Rod. Alagoinhas- \\ Salvador, Km 03, Zona Rural. Alagoinhas-BA (CEP 48.000-000).
}

http://dx.doi.org/10.21472/congrebio2016.et-07-011

\section{RESUMO}

Jogos didáticos podem ser utilizados como uma opção no processo de ensinoaprendizagem, sendo uma importante ferramenta pedagógica, permitindo a construção do conhecimento de forma divertida e dinâmica. A proposta deste trabalho consistiu na elaboração, confecção, aplicação e avaliação de um jogo didático, como uma atividade lúdica, que auxiliasse no aprendizado de conteúdos do Componente curricular de Ciências, por estudantes do $6^{\circ}$ ano do Ensino Fundamental II numa Escola do Município de Alagoinhas-BA, o Colégio Estadual Luis Navarro de Brito. O jogo “Twister Estelar” foi desenvolvido pelos pibidianos, orientados pela professora regente e a Coordenadora de Área, baseado nos conteúdos de Astronomia, especificamente os relativos ao Sistema Solar e na literatura disponível sobre jogos didáticos, sendo aplicado e avaliado pelos aprendentes. Os resultados indicaram a aceitação pelos aprendentes e relação ao jogo, tendo a grande maioria deles aprendido muito sobre o tema abordado, sendo isso feito em clima de alegria, diversão e satisfação. Assim, através desta ferramenta, os conteúdos foram revisados e foram obtidos desempenhos satisfatórios, quando foram questionados sobre o conteúdo. Além disso, o jogo contribuiu para o desenvolvimento e formação profissional dos pibidianos e qualificação da aula da professora regente, podendo ser sugerido como ferramenta no ensino de Ciências.

Palavras-chave: Ludicidade; Ensino; Aprendizagem.

\section{INTRODUÇÃO}

No cenário educacional, novas técnicas didáticas são aperfeiçoadas para garantir um ensino mais eficiente e uma dessas é a ludicidade. A evolução do significado da palavra "lúdico" deixou de ser meramente o sinônimo de jogo e passou a ser interpretada como atividades que possibilitam momentos de prazer, entrega e integração dos envolvidos, promovendo o desenvolvimento de habilidades como: a cooperação, autonomia, estratégia e aceitação de regras.

O jogo didático como método pedagógico é aquele criado com a finalidade de proporcionar aprendizagem diferenciada, sendo distinto do material didático por existir aspecto lúdico (CUNHA, 1988) e utilizado para atingir objetivos pedagógicos, tornando-se uma alternativa de intervenção para melhorar o desempenho dos estudantes em alguns conteúdos de difícil aprendizagem (GOMES et al., 2001). Pode-se destacar que a atividade lúdica tem se mostrado, ao longo dos anos, um método eficaz, interativo e divertido de facilitar a aprendizagem do estudante, apresentando-se como uma alternativa a mais para o professor, como útil ferramenta no processo de ensino-aprendizagem. Podendo ser aplicado como recursos que auxiliam na construção do conhecimento em qualquer área do ensino (ANTUNES, 2010). 
Sendo indicados e recomendados nos Parâmetros Curriculares Nacionais (PCNs) como um recurso auxiliador no processo de aprendizagem.

A formação para utilização de atividades lúdicas possibilita aos profissionais de educação um autoconhecimento, já que este passa a reconhecer suas potencialidades de criação. Isso permite romper resistências e ter uma perspectiva clara sobre a importância do jogo para a vida do discente. Porém, ainda é um problema no ensino, porque educadores ainda não utilizam de recursos desta natureza, que proporcionem o aprendizado de forma lúdica e dinâmica e que seja importante para a formação do sujeito. O que se vê, muitas vezes, na prática pedagógica das escolas, é a falta de interesse dos discentes frente ao que é proposto pelos docentes, que quase sempre propõe atividades e métodos tradicionais.

Os professores frequentemente encontram muitos desafios em sala de aula. Isso decorre da falta de tempo, pouco conhecimento tecnológico e até mesmo da ausência de disposição para inovar. O que acaba restringindo o conteúdo a ser trabalhado somente ao uso de livros didáticos, tornando o ensino, na maioria das vezes, algo repetitivo e pouco motivador. No entanto, os jogos didáticos, bem formatados para trabalhar os conteúdos, disponibilizam aos estudantes uma forma prazerosa e divertida de aprender. O uso de jogos é inovador e atraente e torna o conteúdo agradável e a aula animadora, o que possibilita a conquista preciosa da atenção dos educandos.

De acordo com Miranda (2001), através do jogo didático, vários objetivos podem ser alcançados, relacionados à cognição: afeição; socialização; motivação e criatividade. Assim, ele torna significativo um determinado conteúdo para os aprendentes e a aprendizagem é facilitada.

De acordo com Neves et al. (2008), os jogos didáticos desempenham a função de eficientes recursos auxiliares, já que estimulam a aprendizagem e o interesse por parte dos aprendentes, facilitando para os professores alcançarem seus objetivos nas aulas de Ciências e Biologia. Coloca o docente na condição de condutor, estimulador e avaliador da aprendizagem, na medida em que propõe estímulo ao interesse do estudante pelas aulas.

O jogo não é a desfecho, fim, mas o eixo que dirigi a um conteúdo didático específico, gerando como consequência em uma cessão da ação lúdica para a aquisição de informações (Kishimoto, 1996). Servem como instrumentos auxiliadores de apoio para o professor, portanto não deve ser a única estratégia didática para aquisição de conhecimento. Devem ser vistos como suporte, não substituindo outros métodos de ensino para o professor, tornando-os motivadores eficazes para os aprendentes que desfrutam deste recurso (ZANON et al., 2008).

O ensino sobre o Sistema Solar, conteúdo de Astronomia em Ciências ocorre, em geral, de forma tradicional. Muitas vezes apresentado somente com ilustrações dos livros didáticos, recorrendo-se à memorização de conceitos e nomes. Nessas condições, o conteúdo torna-se tedioso e monótono, fazendo com que os estudantes se tornem menos motivados. Por isso a importância dos professores buscarem alternativas de se trabalhar tais conteúdos, a fim de que as aulas se tornem mais interessantes.

\section{OBJETIVO}

O objetivo deste trabalho foi avaliar a relevância do jogo "Twister Estelar” como uma atividade lúdica para melhoria da aprendizagem de discentes do ensino fundamental numa escola pública do município de Alagoinhas-BA.

\section{METODOLOGIA}

A ideia foi facilitar a aprendizagem dos estudantes sobre as características, assim como, o posicionamento dos planetas diante do sol. Assim, o jogo didático "Twister Estelar" foi construído, como uma adaptação ao jogo "Twister”, patenteado por Charles F. Foley e Rabens Neil, em 1966.

O material elaborado propõe a solução de problemas apontados e revisão dos conteúdos já trabalhados em aula expositiva pela professora regente. O jogo "Twister Estelar" consistiu de um tapete feito de papel metro, tendo o Sistema Solar desenhado, dividido em 20 quadrados, 
onde cada um foi intitulado de "casas". As órbitas nas quais os planetas estavam inseridos foram identificadas com as letras A, B, C, D, F e H (Figura 1). Além disso, dispunha de uma roleta, feita de papel cartolina e isopor, que possuía forma de circulo e o número de casas encontradas no tapete, com desenhos de partes do corpo (mãos e pés). Cartões com perguntas também compunham o jogo.

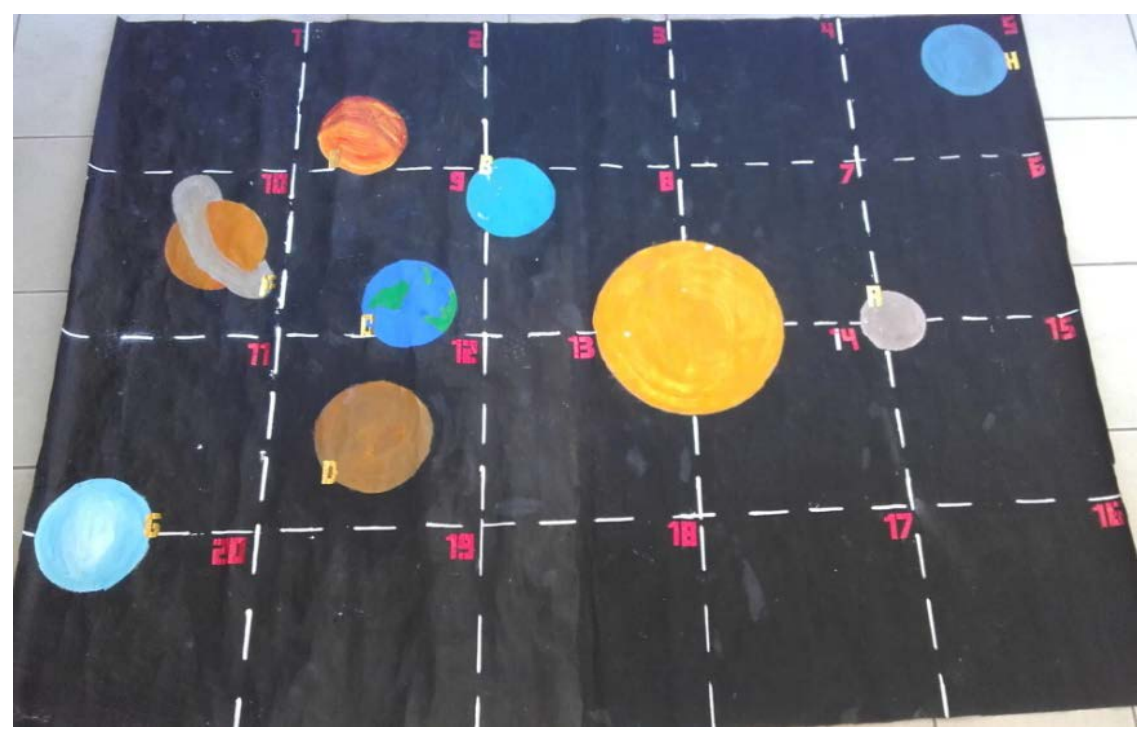

Figura 1. Jogo Twister Estelar, adaptado do jogo “Twister”, patenteado por Charles F. Foley e Rabens Neil, em 1966. Fonte: Arquivo Pessoal.

\section{Regras do Jogo}

Em linhas gerais o jogo deverá seguir a seguinte dinâmica: a turma será dividida em quatro ou cinco equipes de no máximo cinco pessoas. O número de equipes e de componentes deve ser compatível com o número de alunos da classe onde o jogo será aplicado. Cada equipe deve escolher um integrante para ocupar o tapete. Os aprendentes definirão qual equipe de jogadores dará inicio ao jogo, o que pode ser feito numa disputa de dado (numerado de um a seis).

O jogo será dividido em rodadas, onde cada grupo tem o direito de rodar a roleta, que indicará o número da casa e qual membro do corpo o participante que esta sobre o tapete deverá se posicionar, e em seguida responder a pergunta da vez. Em cada rodada, as equipes devem fazer com que o seu grupo acerte o maior número possível de cartas, para que o integrante que esteja no tapete consiga posicionar seus membros. Para isso, os jogadores das equipes devem indicar qual a posição do integrante que está sobre o tapete, em relação à casa, orbita e proximidade ou distância do sol. Por exemplo, se a casa sorteada caiu em cima do planeta Marte, sua posição será no planeta marte, próximo ao planeta Terra e, no quarto planeta próximo ao Sol. Assim, deve responder à pergunta referente aquela casa encontrada nas cartas. Um jogador da equipe deve ser selecionado a cada rodada para ler as cartas com as perguntas, sendo este o locutor da vez. É importante que todos os alunos sejam, pelo menos uma vez, o locutor da jogada.

Caso o grupo erre a resposta, o aprendente que se encontra sobre o tapete não posicionará os membros. Sendo a primeira pessoa que conseguir posicionar os membros inferiores e posteriores em equilíbrio, diante do sistema solar, a ganhadora da rodada. Bem como, aquele que, por ventura, desequilibrar e cair em cima ou colocar mais de um dos membros de uma vez, será desclassificado do jogo, dando à oportunidade a outra pessoa. Caso o jogador considere que a nova posição é impossível de ser sustentada ou que o fará cair, este deve entregar o jogo, admitindo sua derrota. 
Após a realização do jogo, os aprendentes responderam a um questionário, composto por seis questões objetivas e abertas, de linguagem simples, que foi preparado com objetivo de averiguar se o jogo funcionou como uma ferramenta de revisão e ampliação do conhecimento. Assim como, se de alguma forma promoveu interação entre os estudantes; se apreciaram o jogo; se sentiram dificuldades em responder as perguntas; se o jogo necessitava de alterações e se alguma vez fizeram uso de jogos didáticos no ensino de Ciências. A partir da análise das respostas aos questionários, foi feito um gráfico no programa Excel.

\section{RESULTADOS E DISCUSSÕES}

Da turma de discentes participantes do jogo, um total de 24 discentes, os resultados mostraram que, cerca de $90 \%$ consideraram o jogo fácil de ser executado, sem dificuldades para responder as perguntas (Figura 2).

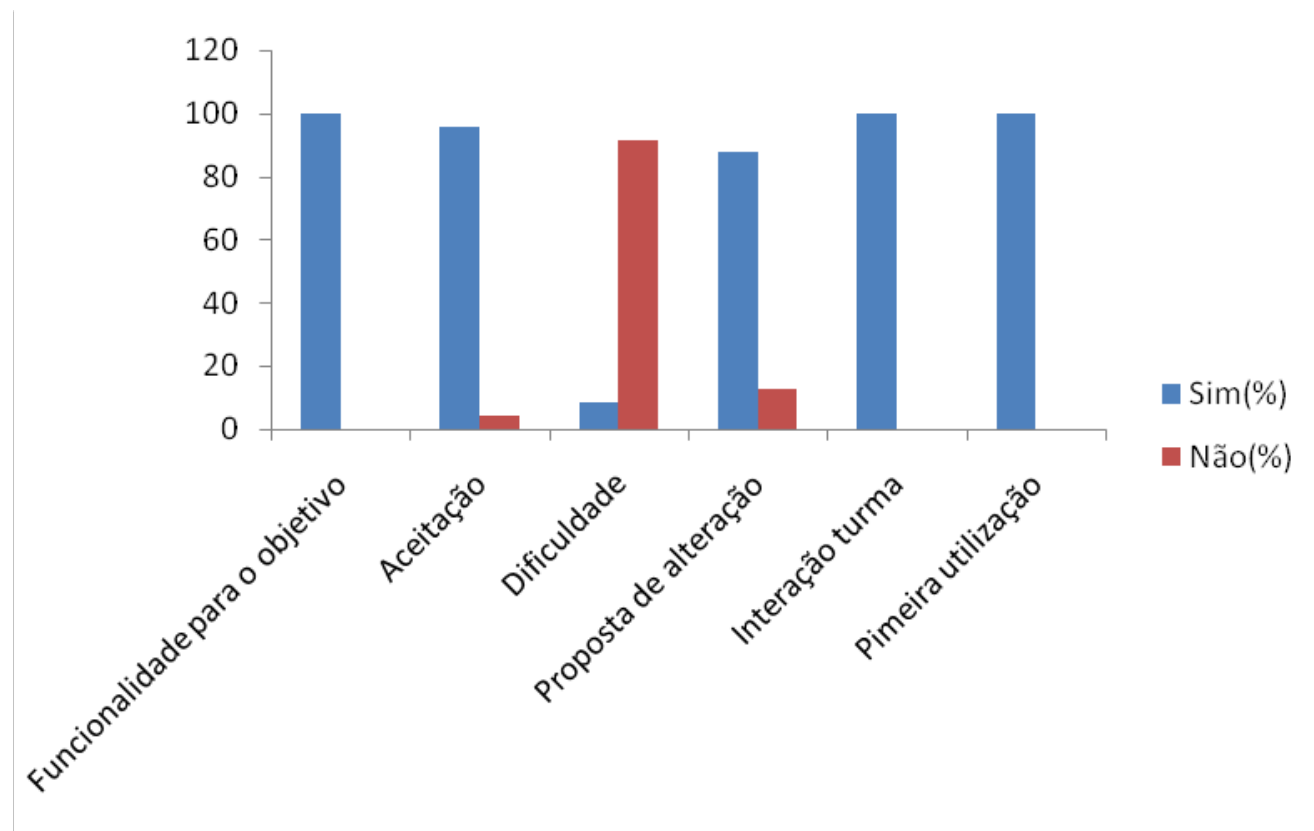

Figura 2. Opinião dos aprendentes do $6^{\circ}$ ano, do Colégio Estadual Luis Navarro de Brito, sobre o jogo “Twister Estelar”. Alagoinhas-BA, abril de 2016.

A maioria dos aprendentes aceitou bem a utilização do jogo na classe e foi verificado que possibilitou uma revisão divertida e eficaz do conteúdo, sendo considerado um importante auxiliador no processo educativo. Os outros $8 \%$, julgaram que o jogo possui um nível médio de dificuldade, pois mesmo após a revisão, ainda tinham algumas dúvidas. Este resultado demonstra que o jogo está adequado para classe quanto ao nível de complexidade das perguntas e reitera ainda mais a ideia de utilização de jogos didáticos como fortes aliados para mediar à aprendizagem de conteúdos abordados e m sala de aula.

Quanto à funcionalidade do jogo, 100\% dos discentes afirmaram que este foi um bom instrumento de revisão e ampliação do conhecimento, uma vez que permitiu a estes que revisassem conceitos, a posição dos planetas e assimilassem conteúdos que antes não entendiam. Assim, pode-se afirmar que o jogo serviu de estímulo para assimilação e aquisição de novos conhecimentos. O ingresso de jogos didáticos no âmbito escolar é fundamental, devido à influência que os mesmos exercem frente aos educandos, já que quando eles estão envolvidos 
nesta atividade, torna-se mais fácil e dinâmico o processo de ensino e aprendizagem (SANTANA, 2008).

Em relação à questão do favorecimento do jogo à interação entre os estudantes. Todos afirmaram que o jogo foi útil neste sentido, uma vez que para o sucesso do grupo, precisou haver colaboração entre eles, o que possibilitou uma maior socialização na turma. Como afirmam Rizzi e Haydt (1986), é jogando que o individuo compreende o valor da equipe, como força integradora e da colaboração consciente e espontânea desta.

Ao se indagar sobre as possíveis sugestões dos estudantes para a melhoria do jogo, 88\% disseram que não havia necessidade. Houve muito elogio ao jogo, com justificativas como: "porque foi muito divertido, animado, educativo, me ensinou mais sobre os planetas". Os 13\% de aprendentes que afirmaram que o jogo precisa de alterações, justificaram sugerindo mudança em uma regra especifica: se o grupo errar a pergunta, ficará uma rodada sem jogar. O que mostra o quanto estes gostaram do jogo, a ponto de que não quererem ficar nenhuma rodada sem participar.

Todos os aprendentes disseram nunca ter participado ou feito uso de jogos no componente curricular Ciências. Ressaltaram a importância da utilização desta ferramenta e expressaram como foi divertido jogar na aula, justificando que saíram da rotina, em que se utiliza somente o quadro negro e livros didáticos para exposição dos conteúdos, uma realidade que atualmente é bastante comum em diversas escolas públicas. Os jogos didáticos são um bom exemplo de recurso para tornar as aulas repetitivas e, muitas vezes cansativas, em algo prazeroso. No entanto, os jogos didáticos devem ser utilizados como mais um recurso na execução de uma aula e que o professor não deve se basear somente nesta ferramenta.

Assim, das análises feitas e de conversas informais com os aprendentes, pode-se perceber uma ampla aceitação e apreciação do jogo "Twister Estelar" e que houve aprendizagem do conteúdo trabalhado, mas de uma forma leve, prazerosa e divertida. Assim, pode-se perceber no jogo uma ferramenta motivadora e integradora, além de propiciar uma socialização entre a turma e auxiliar a docente e os pibidianos na aula.

\section{CONCLUSÃO}

A utilização do jogo didático “Twister Estelar” foi relevante para os aprendentes, facilitando a aprendizagem do conteúdo trabalhado, favorecendo o estímulo à participação na aula.

Na aplicação do jogo, foi notável uma atmosfera de entusiasmo e empolgação, que envolveu os aprendentes, favorecendo o trabalho em grupo e maior integração entre eles, tendo a competição desencadeada entre os grupos, assumindo uma forma muito saudável.

Assim, os pibidianos enquanto profissionais da educação em formação perceberam que o interesse do professor em trabalhar atividades lúdicas com os aprendentes é fundamental para a aprendizagem, para obtenção de um clima adequado para a investigação e a busca de soluções. Mas que deve ser um trabalho continuo para a obtenção de melhores resultados, cabendo ao docente aprimorar e atualizar sempre suas práticas e recursos disponíveis.

Enfim, reitera-se aqui que o jogo didático é um ótimo recurso para auxiliar no processo de ensino aprendizagem, pois a partir do jogo "Twister Estelar" os alunos conseguiram se apropriar de conceitos, das posições dos planetas no Sistema Solar, das informações acerca do Universo e seus corpos celestes, de uma forma atraente, envolvente e divertida.

\section{AGRADECIMENTOS}

À CAPES pela concessão da bolsa resultando no sucesso da pesquisa, ao Colégio Estadual Luiz Navarro de Brito e a professora regente Simone de Fátima Lima Bispo dos Santos por permitir o desenvolvimento do projeto. A Noêmia Barreto dos Santos, Hilton Fernandes e Renata Simões Souza pela confecção do jogo. A todos que direta ou indiretamente colaboraram com o projeto. 


\section{REFERÊNCIAS}

ANTUNES, C. Jogos para a estimulação das múltiplas inteligências. 17. ed. Petrópolis: Vozes, 2010.

CUNHA, N. Brinquedo, desafio e descoberta. Rio de Janeiro: FAE. 1988.

GOMES, R. R.; FRIEDRICH, M. A Contribuição dos jogos didáticos na aprendizagem de conteúdos de Ciências e Biologia. In: EREBIO, 1, Rio de Janeiro, 2001, Anais..., Rio de Janeiro, 2001, p.389-92.

KISHIMOTO, T. M. Jogo, brinquedo, brincadeira e a educação. Cortez, São Paulo, 1996.

MIRANDA, S. No Fascínio do jogo, a alegria de aprender. Ciência Hoje, v. 28, p. 64-66, 2001.

NEVES, J. P.; CAMPOS, L. L.; SIMÕES, M. G. Jogos como recurso didático para o ensino de conceitos paleontológicos básicos aos estudantes do ensino fundamental. Terr@ Plural, v. 2, p. 103-114, 2008.

RIZZI, L.; HAYDT, R. C. Atividades lúdicas na educação da criança. São Paulo: Ática, 1986.

SANTANA, E. M. A Influência de atividades lúdicas na aprendizagem de conceitos químicos. In: SENEPT, 2008, Belo Horizonte. Anais... São Paulo: Universidade de São Paulo, Instituto de Física - Programa de Pós-Graduação, 2008. p. 1-12.

ZANON, D. A. V.; GUERREIRO, M. A. S.; OLIVEIRA, R. C. Jogo didático Ludo Químico para o ensino de nomenclatura dos compostos orgânicos: projeto, produção, aplicação e avaliação. Ciências \& Cognição, v. 13, p. 72-81, 2008. 